\title{
MANAGING ALCOHOL AND DRUGS IN EVENT AND VENUE SETTINGS: THE AUSTRALIAN CASE
}

\author{
ROB HARRIS,* DEBORAH EDWARDS,* AND PETER HOMEL $\dagger$ \\ *Australian Centre for Event Management, UTS Business School, University of Technology, \\ Sydney, Australia \\ †Crime Reduction and Review Program, Australian Institute of Criminology, Sydney, Australia
}

\begin{abstract}
One of the major challenges of operating events and venues is that of managing attendee/patron alcohol and drug use. In the Australian context, a rising number of alcohol and drug-related incidents in and around these settings have resulted in a renewed focus on how these negative outcomes can be more effectively controlled. In order to aid those charged with the task of addressing this matterevent and venue managers, police, security firms, alcohol and drug regulatory bodies, and governments at all levels - this article seeks to identify those variables with the potential to impact this management issue. Further, it aims to provide the previously identified stakeholders with a deeper appreciation of the raft of practices that are currently in use, and potentially available to them, as they build responses to this challenge at the individual state, precinct, venue, or event level. The research approach used involved an extensive literature review and a series of in-depth interviews with key stakeholders across three states—New South Wales, Victoria, and Western Australia.
\end{abstract}

Key words: Drugs and alcohol; Events and venues; Regulation; Enforcement; Control practices

Introduction

Pressure from the broader community on key stakeholders (i.e., events and licensed venues, government at all levels, police, alcohol licensing bodies, crowd controller/security firms, and industry associations aligned to the area) involved in responding to the challenge of managing alcohol and drug use in event and venue settings has increased markedly in Australia in recent years. This increased pressure has resulted from the rising number of incidents of individual harm, violence, and community disruption that have occurred in and around these settings. This situation, in turn, has created a need to identify and better understand those factors with the potential to produce such negative outcomes, along with the practices that can be employed to minimize them. This study has been conducted in response to this need.

This article begins by providing an overview of literature germane to: alcohol and drug use in public 
event and venue settings; the Australian alcohol and drug regulatory and enforcement context; and factors serving to influence or exacerbate alcohol and drug-related harm and antisocial behavior in and around events and venues. Insights emerging from this review are then used to frame a semistructured interview protocol. This protocol is employed with selected informants from stakeholder groups with an interest in controlling problems linked to alcohol consumption and drug use in the settings of interest in this study. Findings flowing from the analysis of these interviews are then drawn upon to identify those factors that can potentially impact alcohol and drug management in events and venues. Also resulting from this analysis is a listing and categorization of those management and control practices presently in use in the Australian context in this area. The article concludes by identifying matters that may benefit from further research if the social cost of alcohol and drug use at events and venues is to be reduced.

\section{Literature Review}

\section{Alcohol Consumption and Drug Use in Public Event and Venue Settings}

As locations at which alcohol and/or drugs are often consumed, many public events and venues potentially represent high-risk settings for incidents of violence, antisocial behavior, or personal harm. In the case of public events, up until the mid-2000s relatively little research had occurred specific to this area in either the Australian or international context (Toomey et al., 2006). In more recent times this situation has begun to change, with research being undertaken on matters such as: public event alcohol control strategies and their effectiveness (Lyne \& Galloway, 2012; Palk, Davey, \& Freeman, 2010; Pearson \& Sale, 2011; Toomey et al., 2006); motivations for, and usage of, alcohol and drugs in festival settings (Lim, Hellard, Hocking, Spelman, \& Aikken, 2010; Nemeth, Kuntsche, Urban, Farkas, \& Demetrovics, 2011); linkages between music preference and drug use at festivals (Hesse \& Tutenges, 2012; Lim, Hellard, Hocking, \& Aikken, 2008); trends in illicit drug use (Lim et al., 2010); propensity for alcohol sales to underage and intoxicated patrons (Toomey, Erickson, Patrek, Fletcher,
\& Wagenaar, 2005); and festivals as a place for substance abuse (Hesse, Tutenges, \& Schliewe, 2010).

A key factor in driving this expanded research interest by Australian and international researchers has been a growing appreciation of the scale of individual and community harm that results from the presence of alcohol and drugs in some public event contexts, most particularly events with a youth orientation. Hutton et al.'s (2011) study of the 2009 Schoolies Festival in Adelaide, Australia (a mass gathering of recently graduated high school students) demonstrates the scale that this problem can reach. At this event, an estimated $24 \%$, or approximately 2,500 attendees, presented for onsite care with alcohol-related health problems. Of this number, some $50 \%$ required hospital treatment. It is also the case that many people attending public events are fearful of their personal safety because of alcohol and drug misuse by others. In a UK study, for example, one poll of attendees to music and sporting events found that this was a concern for some $19 \%$ of those sampled (Institute of Occupational Safety and Health, 2012).

Data collected by police at some events also reflect the potential health toll that alcohol and drugs can have in these contexts, particularly those targeting the youth demographic. In the case of the 2014 Big Day Out Music Festival in Sydney (attended by approximately 30,000 people), for example, 241 people sought on-site medical attention for alcohol or drug-related reasons. It was also the case that hundreds (no specific number provided) of patrons, or potential patrons, were ejected or refused entry as they were deemed to be alcohol or drug affected [Australian Associated Press (AAP), 2014]. In extreme cases, drug abuse at youth-focused events has even claimed the lives of attendees, with the most recent incident in Australia being the death of a patron at the Defcon Festival in Sydney in 2013 (Partridge, 2013).

Unlike public events, venues licensed to sell alcohol have attracted significant interest from researchers over many years. This interest has extended to a diversity of matters, including: prediction of, and management strategies for, violence (Graham \& Homel, 2008; Hobbs, Lister, Hadfield, Winslow, \& Hall, 2000; Measham, 2006); environmental and other alcohol or non-drug-related influences contributing to violence (Graham, Bernards, Osgood, 
\& Wells, 2006; Quigley, Leonard, \& Collins, 2003); policies and practices linked to alcohol and drug management (National Drug Research Institute, 2007; Nicholas, 2006; Nusbaumer \& Reiling, 2003; Palk et al., 2010); approaches to policing (Doherty \& Roche, 2003; Victoria Police Licensing Services Division, 2007); and the link between licensed venues and street crime (Ireland \& Thommeny, 1993).

The major catalyst for researcher interest in this area has likely been the level of violence linked to attendance at venues at which alcohol is sold. In the Australian context, research into venues clearly shows that incidences of aggressive behavior and violence are relatively common, particularly among males (Morgan \& McAtamney, 2009), with assaults in and around licensed venues commonly accounting for over $40 \%$ of total assaults recorded (McIlwain \& Homel, 2009). This situation can be exacerbated in situations where the density of venues is high, such as in entertainment precincts, and where trading hours are long — sometimes 24 hours (Chikritzhs, Catalano, Pascal, \& Hendrickson, 2007; Chikritzhs \& Stockwell, 2002; Moore et al., 2014). Additionally, a large number of recorded assaults involve both patrons as well as others who happen to be in the venue's vicinity (e.g., local residents) (Haines \& Graham, 2005).

It is noteworthy that the UK experience parallels that of Australia in this area, with some $70 \%$ of unscheduled accident and emergency attendances at hospitals during peak periods being alcohol related, with the bulk of these stemming from activities linked to the nighttime economy (Moore et al., 2014). This overrepresentation of alcohol-related harm linked to venues can also be seen in a number of other countries (Edwards, 1994).

\section{The Regulatory Context}

The Australian Federal Government, along with state and territory governments, has sought, as many other governments around the world have, to address the issue of alcohol and drug abuse over a number of years. In 2004, for example, the Ministerial Council on Drug Strategy (MCDS) was formed to function as the peak policy and decision-making body in relation to licit and illicit drugs in Australia. The MCDS developed a National Alcohol Strategy in 2006; however, this body ceased to function in June 2011 and the strategy it developed was not extended beyond this time (Ministerial Council on Drug Strategy, 2011). Nonetheless, these developments represented a significant shift in emphasis in defining and prioritizing alcohol-related problems and resulted in an increased focus on matters associated with intoxication, particularly within the public domain (Nicholas, 2006).

This heightened concern over the abuse of alcohol has resulted in the implementation of a variety of regulations and practices aimed at minimizing alcohol intoxication, including: the national requirement that staff involved in alcohol sale and service be trained in the responsible service of alcohol (RSA); strengthening point of sale liquor controls; and localized liquor management plans and accords. As a result of these actions events and venues now face much stricter liquor licensing regulations. In the case of the state of New South Wales, the government has gone further still, introducing a "Three Strikes” policy. This policy results in an escalation of restrictions on an event's or venue's operations if it records violent incidences linked to alcohol or drugs. Ultimately, events or venues that record three such incidences (strikes) can lose their license to sell alcohol (New South Wales [NSW] Office of Liquor Gaming and Racing, n.d.a). New South Wales has also introduced stringent licensing conditions for venues located in one of its major entertainment precincts, Kings Cross in Sydney, where a number of violent incidents have occurred in recent years. These restrictions involve, among other requirements, new patron lock outs after 1:30 am and prohibitions on the sale of high strength alcoholic drinks after certain times (NSW Office of Liquor Gaming and Racing, n.d.b). Such policies do have an effect on alcohol-related incidents, with several studies on the impact of lockouts, for example, showing a significant drop in incidents (Palk et al., 2010; Palk, Davey, Freeman, \& Morgan, 2012).

Although it is the case that government has taken a variety of steps to reduce the negative social impacts flowing from alcohol, it is nonetheless observable that some of these efforts are failing to achieve their desired outcomes. In particular, it appears that intoxicated people continue to be served alcohol at licensed events and venues (Costello, Robertson, \& Ashe, 2011; Donnelly \& Briscoe, 2005). 
This lack of conformance to ensuring alcohol is served or sold in a responsible manner can be attributed to a range of factors, including: inability of service staff to recognize intoxication in patrons; ability of patrons to mask their overconsumption; lack of management support of service staff; avoidance of service staff of negative or aggressive patron behavior; and a low level of service staff experience and training (Costello et al., 2011; Doherty \& Roche, 2003; Gehan, Toomey, JonesWebb, Rothstein, \& Wagenaar, 1999; Lyne \& Galloway, 2012; McKnight \& Streff 1993; Reiling \& Nusbaumer, 2006). It is noteworthy that staff and management training programs have been shown to be effective in dealing with many of these issues and in so doing serve to enhance regulatory conformance (Toomey et al., 2006).

\section{Regulatory Enforcement}

Enforcing the legislative and regulatory regime associated with alcohol and drugs is a matter that commonly falls to government agencies established for this purpose, along with specialist or general duties police. There is considerable evidence that the effectiveness of strategies that aim to restrict the sale and supply of alcohol, such as responsible beverage service programs, liquor accords, restrictions on the access to alcohol by young people, and community prevention initiatives, are contingent upon the presence of a strong and reliable enforcement component (Loxley et al., 2005; National Drug Research Institute, 2007). Enforcement is also often, but not always, informed by liquor licensing requirements that make it mandatory for events and venues to report incidents of violence to police. This regulatory condition, however, is often overlooked, with an estimated $85 \%$ of assaults that occur in hotels and clubs in Australia, for example, going unreported to police (Doherty \& Roche, 2003).

Crowd controllers, defined here as those individuals performing a security and/or crowd management role, play a major part in ensuring licensed events and venues adhere to legislative and regulatory conditions. Various issues have arisen, however, as to how this group performs this task. There have been, for example, a number of alcohol-related incidents of violence and death directly linked to their actions, including the high- profile death of Australian cricketer David Hookes (Prenzler \& Sarre, 2008). Such outcomes are due, at least in part, to the "bouncer" mentality (i.e., that security should be large men reacting to and ejecting patrons after they become intoxicated) that is in evidence among the management of some events, venues, and security firms (Victoria Police Licensing Services Division, 2007). Various studies discredit such an approach, and argue instead for more proactive, nonaggressive practices before patrons become intoxicated (Kenny et al., 2001).

\section{Factors Impacting Efforts to Manage Alcohol or Drug-Affected Event Attendees and Venue Patrons}

Although the presence of alcohol and drugs is a key factor in many incidences of patron self-harm, violence, and antisocial behavior in or near licensed events and venues, it is also the case that various environmental factors have been identified as acerbating these problems. These factors include: low lighting; overcrowding; long queues; poorly maintained decor and seating; high noise levels; the presence of rubbish and waste in or around an event/venue; poor ventilation; long operating hours; patron/attendee access to water and food; and high temperatures (Allsop, Pascal, \& Chikritzhs, 2005; Graham et al., 2006; Morgan \& McAtamney, 2009; Quigley, Leonard, \& Collins, 2003). To this mix of factors can be added: patron/attendee perceptions that aggression is tolerated by management; failure to dissipate groups immediately outside venues; high alcohol prices at events and venues that lead to attendee's "preloading” prior to entry; cheap alcohol promotions; lack of alcohol control by security staff and serving staff; and inadequate access to public transport (Barton \& Husk, 2012; Homel \& Clark, 1994; Hughes et al., 2011; Martin, Freeman, \& Davey, 2013).

Personal characteristics of individual patrons and attendees also play a major role in influencing alcohol and drug use and associated negative outcomes, specifically: age (as noted earlier), gender, and the socioeconomic profile of patrons (Briscoe \& Donnelly, 2001; Chikritzhs \& Stockwell, 2002; Morgan \& McAtamney, 2009). Of these variables, age is arguably the most powerful predictor of risk. In particular, it is common for young adults to view event and venue settings as places for self- 
indulgence and pleasure seeking, which are devoid of, or have few, restraints (Hobbs et al., 2000). Such a view can, and does, lead to excess alcohol consumption and illegal drug taking on occasions and associated acts of violent behavior and self-harm (Meashan, 2004).

\section{Study Aim and Methodology}

The intent of this study is twofold: to determine the mix of factors that key stakeholders involved in regulating and/or managing risks linked to alcohol and drug use in or around venue and event settings see as impacting the level of this risk; and to identify the range of practices that these same groups are presently using to control the extent of this risk.

To progress this enquiry a Project Reference Group (PRG) was established comprised of representatives from the National Drug Law Enforcement Research Fund (NDLERF) (the study's funding body), the Australian Institute of Criminology, and six senior Australian police officers drawn from New South Wales, Victoria, Western Australia, and Queensland. The latter were chosen by NDLERF, in association with the researchers, on the basis of their extensive experience in alcohol licensing and/or the provision of advice to liquor licensing bodies, events, and venues as regards alcohol and drug-related management and associated issues. The specific role of this body was primarily to serve as a resource for researchers and to assist in identifying, and facilitating access to, organizations and individuals for interview purposes.

The study's literature review served to provide the basis for the development of an in-depth interview protocol that was then used to conduct a series of key informant interviews. In selecting interviewees a stratified purposeful sampling approach was employed in order to capture the range of perspectives germane to the study (Miles \& Huberman, 1994). A total of 48 interviews were undertaken with individuals from identified stakeholder groups-liquor licensing agencies; general duties police; specialist liquor law enforcement police; licensed hotels/pubs/clubs; stadia; local government; security/crowd controller/event risk management firms; relevant industry associations; and licensed festivals and sporting events. The majority of these interviews were with individuals; however, on occasions, interviews involved several people from the one organization. The latter were conducted with larger organizations (i.e., police services and stadia) where it was felt a diversity of perspectives and/or experiences would exist. By acting to seek out a multitude of "stories" and "story tellers" it was intended to produce a more balanced view of the matters being researched in this study (Boje, 1995).

Within each stakeholder group, individuals were selected initially by the researchers with input from the PRG. A “snowballing” approach (Paton, 2002) was then adopted to identify additional key informant groups or individuals as deemed necessary, with redundancy being the trigger for reframing from further interviews. Interviews were primarily undertaken on a face-to-face basis; however, on occasions where this was not possible, telephone interviews were conducted. In order to gain a broader geographic perspective on the issues of concern to this inquiry interviewees were drawn from three states-Western Australia (Perth and Fremantle), Victoria (Melbourne and Geelong), and New South Wales (Sydney and Newcastle). These states were chosen at the request of the PRG who were of the view that they would be representative of what was occurring nationally concerning the matters of interest to the study, while also taking into account the resource limitations of the inquiry. All interviewees chose to remain anonymous and were randomly allocated identifying numbers. Interviews were undertaken between April 2012 and February 2013.

Data gathered through the interview phase of this study were analyzed using the NVIVO qualitative software package. Through an iterative process of engagement with the data facilitated by this package, researchers were able to identify and classify both key influences linked to the potential for drug and alcohol related harm, violence, and community disruption, and practices in use to reduce these negative outcomes.

As with any study, there are limitations attached to the approach used. Key among these in this case are the potential for bias given the involvement of the PRG in the interview selection process, the nonrandomized nature of interviewee selection, and the absence of a number of Australian states from the study. Although not dismissive of these matters, 
the substantial degree of commonality of responses given by interviewees from within the various stakeholder groupings suggest that the study's findings adequately capture current perspectives on the matters of interest here, along with the bulk of regulatory and other practices currently in use.

\section{Results}

Eight broad generic factors were identified as having the potential to influence the likelihood of patron/attendee harm, and the level and type of violence and antisocial behavior at a given event or venue where alcohol and/or drugs were present. Additionally, a large number (50) of practices intended to minimize or eliminate these negative impacts were identified that were able to be grouped under five general headings based on their intent.

\section{Factors Impacting Patron/Attendee Harm, Violence, and Antisocial Behavior}

Nature of Alcohol and Drugs Consumed. All interviewees agreed that there was a correlation between the types of alcohol and drug consumed by patrons/attendees and incidences of personal harm, violence, or antisocial behavior. In the case of alcohol, the strength (in terms of alcohol content) of drinks sold was seen as key in controlling negative incidents. Interviewees representing stadia and sporting events, for example, noted a significant reduction in problems linked to alcohol when they had moved from selling full-strength to low- or mid-strength beer. Indicative of such outcomes are the comments of one stadium manager who observed that:

We don't have a lot [of incidents of violence] and most of those if we do have them relate primarily around the consumption of alcohol. Now that's changed in recent years for us. We've [sic] gone to a fully mid strength venue so we've improved our crowd behavior enormously in those events that were challenging in the past. (Participant 10)

The efforts of events and venues to reduce alcohol-related incidents via changes to alcohol strength can, as many interviewees noted, be circumvented. This occurs through attendees/patrons consuming alcohol prior to arrival (preloading) or who smuggle it in (side loading). Both of these practices were identified as being driven largely by price, with one alcohol licensing body staff member observing that:

A huge price differential (exists) between what a nightclub sells a drink for, or can sell drinks for, to what people can go to [a retail liquor outlet] and buy a drink. (Participant 04)

It was further noted that operating hours were a factor in preloading as:

[T]he clubs are trading so late ... they're [patrons] not planning to go out until 11:00 or midnight, you know what are they doing between 6:30 and that time and what they're doing is anecdotally is people are sitting at home or around at a mate's place where they've bought cheap booze and drinking and then they go out later half charged and that's where our problems start. (Participant 01)

Additionally, preloading was seen as potentially difficult to detect as one venue association representative observed:

We have our licensees say to us things like "Someone walks into my venue. They look fine. Thirty minutes later it's kicked. Thirty minutes when it's kicked in. How do I control that?” They can't. That's the argument. (Participant 77)

Drug use was acknowledged as a significant problem in some contexts. In particular, certain types of venue-based events were singled out:

Certain scenes, if you like, are more conducive to the illicit drug users and that's broadly the dance scene, if you like, dance, obviously dance parties and rave parties and that type of thing. You're more likely to get your pill poppers and those and want to take GSB. (Participant 42)

The type of drug being used by attendees/patrons was also seen as key in determining its impact on behavior, with "softer" drugs such as marijuana being viewed as having little effect, while drugs such as "ice" (part of the amphetamine family of drugs) were identified as particularly problematic as they could result in aggressive and violent behavior.

As was noted in the case of alcohol, a number of interviewees stated that it is not uncommon for some attendees/patrons to seek to smuggle drugs into an 
event or venue, or to preload. Given this, police and security industry interviewees emphasized the importance of practices designed to minimize the success of such efforts, such as bag-checking procedures and drug-detection dogs at entry points. These practices, however, had, as several venue and event managers noted, resulted in incidents of personal harm when quantities of drugs were consumed quickly to avoid possible detection.

Attendee/Patron Profile. In general terms, younger age groups, as identified in the literature review, were considered by interviewees to present a higher risk of engaging in behavior of a violent or antisocial nature, as well as suffering from the ill effects of alcohol consumption and drug use. The reasons given for this were mainly a lack of education around responsible drinking and drug use, cultural norms, and factors associated with their incomplete physical and biological development. As one interviewee put it:

Kids are kids, they are young and dumb, they are going to get drunk, some are going to get drunker than others, we've got to create a safe environment and have the systems to pick them up if they fall down, from medical through the- [sic] thing and the cultural issues are much broader, it's nothing we can do. (Participant 30)

Several event organizers highlighted the benefit of mixing age demographics as this strategy had a positive impact on the behavior of younger patrons, with one festival manager noting:

The more families, the more kids, the better the crowd behavior. Because it also stops the idiots from being poorly behaved as well, where they're sitting among families. It's a great leveler in some ways. (Participant 10)

There was also general agreement that males were more likely to be involved in violent incidents, but concerns were expressed that:

You've still got more fights between women now in premises or on the streets. (Participant 04)

Interviewees from stadia drew attention to the issue of sporting events where a "tribal" culture sometimes exists among fans. In these instances such a culture, when combined with alcohol consumption or drug use, has the potential to result in significant outbreaks of violence and antisocial behavior. From the perspective of venues operating in the nighttime economy, it was also observed that groupings of associated individuals could be problematic as they tend to move from one venue to another, which can lead to opportunities for conflict.

I'll see that same group in Oxford Street later and then later on I'll see them again in Kings Cross. So they're migrating, the more they migrate, the more chance they have to come across other groups and that's where the conflict emerges in the street. (Participant 04)

Event Type and Associated Entertainment. Events or venues with more "sedate" programs or acts (e.g., family-based festivals) were deemed to be less of a risk in terms of violence, antisocial behavior, or patron harm than "high energy" events such as dance or rave parties and youth-oriented music festivals, essentially because of the younger audience they attracted.

Understanding the history and fan base of acts engaged to perform at events and venues was also identified as an important consideration by several interviewees, as performers commonly draw a certain type of crowd with particular characteristics that may impact alcohol consumption, drug use, and behavior (e.g., crowd surfing, vigorous forms of dancing).

Site/Venue Layout/Design and Operational Considerations. As was identified in the literature review, interviewees drew attention to event and venue design and layout matters that could exacerbate alcohol and drug management issues. In this regard, poor lighting, narrow walkways, and congested entry and exit points were seen as particularly problematic. These factors were considered to create situations in which patrons may believe that they cannot be observed and can therefore engage in violent or antisocial acts. Additionally, these factors can create "flashpoints" for violence as they make it easier for alcohol or effected patrons to bump into one another, particularly in crowded situations.

The boredom and tension associated with waiting in entry and service queues, when coupled with 
the consumption of alcohol or drugs, was highlighted by many interviewees as a potential trigger for violence. Indicative of such views was that of one hotel owner who stated that:

If you've got your queues for the bar and people have to get through to get to the toilets or to the food, you get aggro cos [sic] people think they're trying to push in in the line or you know and if they've had a few and they're stumbling through, banging into people. They need to look at their layouts cos [sic] queues really [expletive] people. (Participant 27)

Event/Venue Location and Environs. The location of an event or venue was seen as having implications for controlling incidents of violence and antisocial behavior. City-based venues, or events taking place in city locations, were identified as presenting a higher risk profile due to the presence of other licensed premises in their immediate vicinity. Additionally, as intoxicated or drug-affected attendees/patrons moved between events or venues the potential existed for them to impact residents, visitors to the area, and businesses. One security firm emphasized this point, noting that:

We do an event called Laneways-it's in the middle of the city. It's tiny, it's only 6,000 people that go, but we need-that's incredibly security intensive because of the nature of the site. We need 80 security for that one. (Participant 30)

Several police drew attention to the need to ensure a perception existed that the event or venue was well managed by, for example, not allowing rubbish to accumulate inside the venue or around entry points, and being quick to deal with graffiti or the like. They also noted that crowds should not be allowed to form around entry points as this potentially increased the potential for violence between alcohol or drug-affected individuals.

Transport Availability. Adequate transport availability for event and venue attendees/patrons was acknowledged by a number of interviewees as key to crowd dispersal postevent, or at closing time. Such dispersal was deemed important in reducing the potential for violence or antisocial behavior immediately adjacent to events or venues, or in surrounding areas. As one interviewee from local government stated:

The issue always becomes when things close and they've got nowhere to go. (Participant 77)

Additionally, it was highlighted that the level of control an event or venue has over the availability of transport can differ significantly. Interviewees from stadia and larger events, for example, indicated that their transport arrangements were often prearranged with public and/or privately owned transport providers. Indeed, such arrangements were commonly a condition of their liquor licenses. However, a number of interviewees from clubs made the point that due to their late night trading hours, transport could present significant problems. The essence of this problem is evident from the comments of one nightclub manager who stated:

In Melbourne trains stop at 1:00am. They bring in hundreds and thousands of people on Friday and Saturday nights who can't get a train home till 5:00 or 5:30 in the morning. (Participant 04)

Regulation, Enforcement, and Managerial Oversight. Although event and venue managers interviewed were essentially aware of their legal and regulatory responsibilities linked to matters such as the responsible service of alcohol, staff training, security requirements, and trading hours, some indicated that fulfilling some of their obligations in this area was at times problematic. Several made the point that if an attendee/patron was identified as intoxicated, which meant they were required by the conditions of their license to eject them from their premises/site, they were simply transferring the problem to the street outside or surrounding area. Additionally, there was a view among event and venue managers that it was sometimes difficult for their staff to identify intoxicated patrons and exclude them or stop serving them. Indicative of such a view was that of one hotel venue manager who stated in connection with bar sales of alcohol at his property:

The problem is, they [the patrons] are pretty onto it, and they'll straighten up and try and act sober. And they'll do that again going up to the bars. They know how to act. (Participant 30) 
Compounding this problem, this same interviewee argued, was the small period of time staff have to assess patrons before deciding to serve them or not. Police and alcohol licensing bodies interviewed, however, were not overly sympathetic to such arguments. Instead, they took the view that too often commercial pressures led servers and crowd controllers to turn a "blind eye" to incidents of intoxication. In this regard one police interviewee put forward the perspective that:

The vast majority of licensed premises do not adhere to the responsible service of alcohol. (Participant 74)

Indeed, several interviewees from these groups drew attention to the difficulties they faced from "cowboy" operators at times, and the varying extent to which license regulations were being adhered to on an ongoing basis.

It was suggested by police interviewees that some events and venues were not reporting incidents of violence, as they are required, to avoid greater police scrutiny and to prevent their alcohol licenses being placed in jeopardy. Support for this view was provided by some of the security firms interviewed who stated that, at times, their staff were discouraged from reporting incidents by event and venue managers.

Concerns were raised as to the personal characteristics and training level of those working in the crowd controller area, or seeking to enter it. Common matters identified in this regard were: English fluency; lack of prior cultural exposure to alcohol and drugs and their effects; limited interpersonal skills; and quality of training received. The former was of particular concern in the control of violent incidents, with one security firm owner noting:

Some of the problems here is the English not being the first language. It [lack of English] then is more likely to, any incident is more likely to then necessarily result in the use of force because there are communication barriers. (Participant 72)

A key driver of this situation was identified as the relatively low pay rates which results in:

The people who are now applying to become security [guards] are genuinely your recent immigrants. (Participant 84)
Level of Collaboration. Collaboration between stakeholders was acknowledged by a number of interviewees as a key factor in the safe operation of events and venues. A number of event and venue managers, for example, had worked with police to identify and plan for potential alcohol and drug-related risks, ensure their staff and contractors were clear on their regulatory responsibilities (via police briefings), and to enhance their on-site security (through the engagement of user paid police). While acknowledging the value of working with police, several event and venue managers also argued that they could be overly authoritarian towards their patrons, subjecting them at times to what they considered unnecessary searches, and undertaking overly frequent licensing inspections.

There was a strong view held by local government interviewees, along with most police and alcohol licensing bodies, that a holistic approach to alcohol and drug management involving multiple stakeholders was particularly valuable in instances where venues where located in close proximity to one another . It was argued by one local government interviewee with experience in this area that such an approach served to foster open communication, the sharing of information, and generally resulted in improved outcomes:

If we all work together and we communicate and we sort of line up what we do we can be a whole lot more effective than if we're fragmented. (Participant 86)

Various examples were cited by interviewees from the police and local government where such collaborative efforts had been successful: the Newcastle Alcohol Management Strategy, Greater Geelong Integrated Alcohol Response, Melbourne Licensee Forum, and the City of Sydney Liquor Accords.

\section{Practices}

When viewed collectively, the practices in use by stakeholders to reduce the negative consequences of drug and alcohol use in event and venue settings were found to fall under five broad headings: entry controls; alcohol service controls; attendee/patron management; site/venue layout/design and environ management; and regulatory and enforcement practices. These practices have been summarized in Tables 1-5. 
Table 1

Event and Venue Alcohol and Drug Management Practices: Entry Controls

- Entry point monitoring—restricts entry by drug effected or intoxicated individuals, underage patrons or previously excluded individuals.

- Searches at entry points to exclude drugs and alcohol—bag searches, body pat-downs, and use of sniffer dogs by police.

- Fencing - reduces the potential for drugs/alcohol to be brought onto an event site, or for intoxicated patrons to enter or reenter once they have been excluded.

- Use of ID scanners - serves to remove the anonymous nature of venue attendance, reduces the potential for individuals with prior recorded incidents of drunken or violent behavior to reenter, and assists in identifying individuals that are underage. Venue ID scanners are sometimes linked so that data relating to problem individuals can be shared between venues located in close proximity to one another.

- Exclusion of individuals wearing gang insignia or "uniforms"- gang members are prone to initiating acts of violence, and some use events and venues as markets for illegal drugs.

- Codes of conduct and regulations associated with alcohol service- displayed at entry points and sometimes online, these serve to communicate behavior requirements, age restrictions, dress, and other entry conditions.

- Strict maintenance of venue/event capacity limits by such means as capping ticket sales/entry numbers to avoid overcrowding and the potential for intoxicated or drug-affected attendees/patrons to come into contact with one another.

Table 2

Event and Venue Alcohol and Drug Management Practices: Alcohol Service Controls

- Licensed-based, or voluntary, restrictions on the types of alcohol sold (e.g., spirits, double shots) and its alcohol content (e.g., shots, full strength beers) at particular time periods or more generally.

- Provision of alcohol in open containers only to restrict patron "stockpiling."

- Restrictions on the size of containers in which alcoholic drinks are served in order to reduce consumption.

- Placement of limits on the number of alcoholic drinks that can be purchased at any time by a single attendee/patron.

- Reduction in the period of time allocated to, or elimination of, "happy hours" or drink promotions where alcohol is provided at discounted prices.

- Use of identifiers (e.g., risk bands, IDs) to restrict access to alcohol by underage individuals.

- Elimination of some forms of alcohol sales (e.g., shots) after specific times.

- Implementation of exclusion zones/areas where alcohol cannot be served or consumed to restrict the mixing of alcohol effected attendees/patrons with others (most particularly children).

- Elimination of glass serving containers and their replacement with plastic so as to reduce the potential for injury from acts of violence.

Table 3

Event and Venue Alcohol and Drug Management Practices: Attendee/Patron Management

- Provision of food and free drinking water in order to reduce the intoxicating/dehydration effects of alcohol or drugs.

- Monitoring by crowd controllers, nonserving bar staff (e.g., glass collectors) and police (if present) to identify and/or exclude drug or alcohol effected patrons.

- Installation of CCTV systems and the promotion of such to attendees/patrons so as to discourage violent or antisocial acts.

- Enlistment of charity and volunteer groups such as St John Ambulance and Red Frogs to identify, and provide assistance to, intoxicated or drug-affected patrons.

- Inclusion of messages concerning safe drinking practices in promotional material, on websites, and on onsite signage.

- Promotion of peer support messages to encourage patrons to look after their drug or alcohol-affected friends.

- Elimination of 'pass outs' to prevent patrons consuming alcohol at other locations and returning.

- Exclusion orders (permanent or temporary) to prevent individuals returning who have a record of violent or antisocial behavior.

- Use of door charges in the late evening/early morning at venues to reduce the movement of patrons between licensed premises.

- Provision of facilities for the safe disposal of needles and syringes by attendees/patrons.

- Operation and support of designated driver and free shuttle bus programs to reduce the potential for alcohol-related road accidents.

- Progressive shutdowns of venues (i.e., bar by bar) to reduce the tendency for some patrons to quickly consume significant amounts of alcohol prior to closing, and to stagger the demand for transport. 
Table 4

Event and Venue Alcohol and Drug Management Practices: Site/Venue Layout and Design and Environ Management

- Provision of adequate numbers of toilets, food outlets, and bars so as to reduce congestion/queuing times and associated rises in frustration/aggravation.

- Identification and elimination of "pockets" in events and venues where attendees/patrons cannot be easily observed.

- Locating bar areas at events away from the main entertainment areas in order to reduce the ease with which alcohol can be accessed.

- Provision of designated "chill out" areas where attendees/patrons can escape from crowding and loud noise in order to reduce sensory overload and the potential for aggressive behavior.

- Provision of adequate lighting (especially at entry and alcohol serving points) to aid crowd controller and alcohol-serving staff in their attendee/patron monitoring role.

- Maintenance of venue temperature at a comfortable level.

- Allocation of sufficient space for walkways/thoroughfares to reduce the potential for violence born of attendees/patrons coming into contact with one another.

- Creation of alcohol-free areas.

- Facilitation of attendee/patron dispersal by: promotion of transport options/ timetables inside venues/event sites, on tickets and websites; and the development of a comprehensive transport management plan.

- Maintenance of a clean environment in, and around, an event site or venue in order to reflect that it is well managed and therefore unlikely to tolerant inappropriate behavior.

Unsurprisingly, the vast majority of the actions noted by event and venue managers flowed directly from the licensing conditions imposed on them by regulatory agencies (e.g., employment of serving staff trained in the responsible service of alcohol, conducting business within defined trading hours, and elimination of high alcohol content drinks after specific times), or a desire to avoid the possibility of breaking these conditions (the elimination of "happy hours,” use of identifiers designed to reduce the potential to serve alcohol to underage drinkers, reductions in alcoholic beverage container size, and codes of attendee/patron behavior). Some practices, however, were identified that arguably went beyond what was required to maintain a license to sell alcohol. These were largely in the area of patron welfare and included: "chill” out areas for alcohol or drugaffected attendees/patrons; engagement of charities

Table 5

Event and Venue Alcohol and Drug Management Practices: Regulatory and Enforcement Practices

- Defined trading hours-license condition intended to restrict access to alcohol before and after certain times.

- Regulatory requirement for venue or event licensees, serving staff, crowd controllers/security officers to have completed Responsible Service of Alcohol training.

- Randomized or targeted enforcement of venue or event's adherence to licensing conditions by police and/or liquor licensing bodies.

- Use of venue lockouts after specific times so as to restrict the potential for alcohol or drug-affected individuals who have been excluded from one venue moving to another.

- Imposition of escalating penalties/operational limitations based on the number of regulatory infringements.

- Regular checking by police of event/venue incident logs, and their own internal records, to establish the extent to which individual venues or events represent an acceptable patron harm risk.

- Imposition of a licensing requirement that necessitates the use of a set number of user-paid police.

- Use of "out of uniform" police, or liquor licensing staff, to monitor attendees/patrons and/or assess responsible service of alcohol practices.

- Freezes (when deemed necessary) on the issuing of additional liquor licenses in precincts where the concentration of licensed venues had led to an unacceptable number of violent incidents.

- Use of high-visibility clothing for crowd controllers and police to both deter acts of violence and to facilitate their identification by patrons seeking assistance.

- "Grading” of crowd controllers by contracted security firms to assist in ensuring those with higher level communication skills/ experience are placed in areas of higher risk (e.g., event entry points, bar areas).

- Maintenance of an appropriate mix (e.g., static or roving, female vs. male) and ratio of crowd controllers to attendees/patrons based on a comprehensive risk assessment of the event/venue.

- Provision of advice, and/or written guides, by police and/or licensing bodies to events and venues seeking an alcohol license or dealing with heightened levels of alcohol-related harm. 
or welfare groups to provide support to individuals affected by drugs or alcohol; peer support messages to encourage patrons to look after their alcohol or drug-affected friends; and operation of designated driver programs to reduce the potential for road accidents.

In additional to practices in use at the level of the individual venue or event were broader efforts designed to control activities within areas where multiple venues were located in close proximity to one another. These practices were of two types: precinct alcohol management plans (imposed by state or local government) and voluntary community-based liquor accords (involving police, venues, local government, liquor licensing bodies, and relevant community groups). These actions commonly centered on controls on trading hours, training requirements for licensees and staff, patron lockouts after specified times, the imposition of alcohol-free zones, and an enhanced police presence.

\section{Discussion and Conclusion}

Effective alcohol and drug management presents a significant challenge to licensed event and venue managers in the Australian context, and to a range of other groups with a stake in this issue. This study has sought to aid these groups in responding to this challenge in two ways. Firstly, it has identified those variables that potentially condition decision making in this area and so need to be taken into account by these groups. These were found here to be: the nature of alcohol and drugs consumed; attendee/patron profile; event type and associated entertainment; site/venue layout/design and operational factors; event/venue location and environs; transport availability; regulation, enforcement and managerial oversight; and level of collaboration. Secondly, the study's findings enhance the level of awareness among these same groups as to the diversity of practices currently in use from which they may wish to draw as they fashion their own specific response to the challenge of drug and alcohol management. Depending on the nature of the stakeholder group concerned, this response may involve actions in the areas of: entry controls; alcohol service controls; attendee/patron management; site/venue layout/design and environ management; and regulatory and enforcement practices.
Although this study has gone some way towards providing a platform from which decisions in the area of drug and alcohol management in event and venue settings can be made, much still remains to be done from a research perspective. In particular, the efficacy of the measures identified here as serving to mitigate risk need to be evaluated, along with those factors impacting upon them. This study has alluded to what some of these factors might be, specifically: commercial pressures; adequacy of staff and crowd controller training; difficulties in "on the ground" implementation of regulations; and friction between some stakeholder groups as to enforcement practices; however, research specific to this matter would likely significantly expand upon these factors and so further clarify the forces at play.

\section{References}

Allsop, S., Pascal, R., \& Chikritzhs, T. (2005). Management of alcohol at large-scale sports fixtures and other public events. National Drug Research Institute, Curtin University of Technology.

Australian Associated Press. (2014). Police arrested 100 people in an Australia Day operation and another 120 at the Big Day Out in Sydney but say most people were well behaved. Retrieved from http://www.sbs.com.au/news/ article/2014/01/27/100-australia-day-arrests-nsw

Barton, A., \& Husk, K. (2012) Controlling pre-loaders: Alcohol related violence in an English night time economy. Drugs and Alcohol Today, 12(2), 89-97.

Boje, D. (1995). Stories of the story telling organisation: A postmodern analysis of Disney as "Tarmara Land." Academy of Management Journal, 38(4), 997-1036.

Briscoe, S., \& Donnelly, N. (2001). Assaults on licensed premises in inner-urban areas. Alcohol Studies Bulletin No. 2. Retrieved from http://www.popcenter.org/problems/ assaultsinbars/PDFs/Briscoe\&Donnelly_2001b.pdf

Chikritzhs, T., \& Stockwell, T. (2002). The impact of later trading hours for Australian public houses (hotels) on levels of violence. Journal of Studies on Alcohol, 63(5), 591-595.

Chikritzhs, T., Catalano, P., Pascal, R., \& Henrickson, N. (2007). Predicting alcohol-related harms from licensed outlet density: A feasibility study (Monograph Series No. 28). Hobart, Tasmania: National Drug Law Enforcement Research Fund.

Costello, D., Robertson, A. J., \& Ashe, M. (2011). Drink or drunk: Why do staff at licensed premises continue to serve patrons to intoxication despite current laws and interventions? (National Drug Law Enforcement Research Fund, Monograph Series No. 38). Canberra: Commonwealth of Australia.

Doherty, S., \& Roche A. (2003). Alcohol and licensed premises: Best practice in policing. A monograph for police and policy makers. Retrieved from http://nceta.flinders. edu.au/files/7312/5548/1448/EN34.pdf 
Donnelly, N., \& Briscoe, S. (2005). Intelligence-led regulation of licensed premises. In T. Stockwell, P. J. Gruenewald, J. W. Toumbourou, \& W. Loxley (Eds.), Preventing harmful substance use: The evidence base for policy and practice (pp. 257-266). West Sussex: John Wiley \& Sons.

Edwards, G. (1994). Alcohol policy and the public good. Oxford: Oxford University Press.

Gehan, J., Toomey, T., Jones-Webb, R., Rothstein, C., \& Wagenaar, A. (1999). Alcohol outlet workers and managers: Focus groups on responsible service practices. Journal of Alcohol and Drug Education, 42(2), 60-71.

Graham, K., Bernards, S., Osgood, W., \& Wells, S. (2006). Bad nights or bad bars? Multi-level analysis of environmental predictors of aggression in late-night largecapacity bars and clubs. Addiction, 101, 1569-1580.

Graham, K., \& Homel, R. (2008). Raising the bar: Preventing aggression in and around bars, pubs and clubs. Devon, UK: Willan Publishing.

Haines, B., \& Graham, K. (2005). Violence prevention in licensed premises. In T. Stockwell, P. J. Gruenewald, J. W. Toumbourou, \& W. Loxley (Eds.), Preventing harmful substance use: The evidence base for policy and practice (pp. 163-176). West Sussex: John Wiley \& Sons.

Hesse, M., \& Tutenges, S. (2012) Music and substance preferences among festival attendants. Drugs and Alcohol Today, 12(20), 82-88.

Hesse, M., Tutenges, S., \& Schliewe, S. (2010). The use of tobacco and cannabis at an international music festival. European Addition Research, 16, 208-212.

Hobbs, D., Lister, S., Hadfield, P., Winlow, S., \& Hall, S. (2000). Receiving shadows: Governance and liminality in the night-time economy. British Journal of Sociology, 51(4), 701-718.

Homel, R., \& Clark, J. (1994). The prediction and prevention of violence in pubs and clubs. Crime Prevention Studies, 3, 1-46.

Hughes, K., Quigg, Z., Eckley, L., Bellis, M., Jones, L., Calafat, A., Kosir, M., \& van Hasselt, N. (2011). Environmental factors in drinking venues and alcohol-related harm: The evidence base for European intervention. Addiction, 106, 37-46.

Hutton, A., Roderick, A., Munt, R., Kako, M., Mayner, L., \& Arbon, P. (2011). Celebrating end of school life: Do young people think about being safe and healthy when they are out having fun? Pre-hospital and Disaster Medicine, 27(1), 13-17.

Institute of Occupational Safety and Health. (2012). Sports grounds and events group. The Safety and Health Practitioner, 30(4), 26.

Ireland, C., \& Thommeny, J. (1993). The crime cocktail: Licensed premises, alcohol and street offences. $\underline{\text { Drug }}$ and Alcohol Review, 12(2), 143-50.

Kenny, J. M., McPhail, C., Waddington, P., Heal, S., James, S., Farrer, D., Taylor, J., \& Odenthal, D. (2001). Crowd behavior, crowd control, and the use of non-lethal weapons. Institute for Non-Lethal Defence Technologies. University Park, PA: Penn State, Institute for Non-Lethal Defense Technologies.
Lim, M., Hellard, M., Hocking, J., \& Aikken, C. (2008). A Cross-sectional survey of young people attending a music festival: Associations between drug use and musical preference. Drug and Alcohol Review, 27, 439-441.

Lim, M., Hellard, M., Hocking, J., Spelman, T., \& Aikken, C. (2010). Surveillance of drug use among young attending a music festival in Australia, 2005-2008. Drug and Alcohol Review, 29, 150-156.

Loxley, W., Gray, D., Wilkinson, C., Chikritzhs, T., Midford, R., \& Moore, D. (2005). Alcohol policy and harm reduction in Australia. Drug and Alcohol Review, 24(6), 559-568.

Lyne, M., \& Galloway, A. (2012). Implementation of effective alcohol control strategies needed at large sports and entertainment venues. Australian and New Zealand Journal of Public Health, 36(1), 55-60.

Martin, P., Freeman, J., \& Davey, J. (2013). Officers’ perspectives of policing alcohol-related incidents in and around licensed premises. Police Practice and Research: An International Journal, 14(3), 193-204.

McKnight, A. J., \& Streff, F. (1993). The effect of enforcement upon service of alcohol to intoxicated patrons of bars and restaurants. Accident Analysis and Prevention, 26(1), 79-88.

McIlwain, G., \& Homel, R. (2009). Sustaining a reduction of violence in the licensed environment. Brisbane, Australia: Griffith University, Key Centre for Ethics, Law, Justice and Governance.

Measham, F. (2004). Play space: Historical and socio-cultural reflections on drugs, licensed leisure locations, commercialisation and control. International Journal of Drug Policy, 15, 337-345.

Measham, F. (2006). The new policy mix: Alcohol, harm minimisation, and determined drunkenness in contemporary society. International Journal of Drug Policy, 17(4), 258-268.

Miles, M., \& Huberman, A. (1994) Qualitative data analysis: A Sourcebook of new methods (2nd ed.). Thousand Oaks, CA: Sage.

Ministerial Council on Drug Strategy. (2011). National drug strategy 2010-2015. Retrieved from http://www.national drugstrategy.gov.au/internet/drugstrategy/Publishing.nsf/ content/DB4076D49F13309FCA257854007BAF30/\$File/ nds2015.pdf

Moore, S., O’Brien, C., Alam, M., Cohen, D., Hood, K., Huang, C., Moore, L., Murphy, S., Playle, R., Sivarajasingam, V., Spasic, I., Williams, A., \& Shepherd, J. (2014). All-Wales licensed premises intervention: A randomised controlled trial to reduce alcohol-related violence. BMC Public Health, 14(21), 1-7.

Morgan, A., \& McAtamney, A. (2009). Key issues in alcoholrelated violence. Research in Practice No. 4. Canberra: Australian Institute of Criminology.

National Drug Research Institute. (2007). Restrictions on the sale and supply of alcohol: Evidence and outcomes. Perth: Curtin University of Technology.

Nemeth, Z., Kuntsche, E., Urban, R., Farkas, J., \& Demetrovics, Z. (2011). Why do festival goers drink? Assessment of 
drinking motives using DMQ-R SF in a recreational setting. Drug and Alcohol Review, 30, 40-46.

New South Wales Office of Liquor, Gaming and Racing. (n.d.a) “Three Strikes” disciplinary scheme. Retrieved from http://www.olgr.nsw.gov.au/liquor_3_strikes.asp

New South Wales Office of Liquor, Gaming and Racing. (n.d.b), Kings Cross Precinct-Special licence conditions. Retrieved from http://www.olgr.nsw.gov.au/liquor kingscross_precinct.asp

Nicholas, R. (2006). Identifying and responding to problematic licensed premises: A guide for police. Adelaide: Australasian Centre for Policing Research.

Nusbaumer, M., \& Reiling, D. (2003). Where problems and policy intersect: Servers, problem encounters and targeted policy. Drugs: Education, Prevention and Policy, 10(1), 21-29.

Palk, G., Davey, J., \& Freeman, J. (2010). The impact of lockout policy on levels of alcohol-related incidents in and around licensed premises. Police Practice and Research: An International Journal, 11(10), 5-15.

Palk, G., Davey, J., Freeman, J., \& Morgan, H. (2012). Perspectives on the effectiveness of the late night liquor trading lockout legislative provision. Criminal Justice Policy Review, 24(4), 465-492.

Partridge, E. (2013). Man dies at Defqon.1 music festival. Sydney Morning Herald. Retrieved from http://www. smh.com.au/entertainment/music/man-dies-at-defqon1music-festival-20130915-2tsfv.html
Paton, M. (2002). Qualitative research and evaluation methods. London: Sage.

Pearson, G., \& Sale, A. (2011). “On the lash”-Revisiting the effectiveness of alcohol controls at football matches. Policing and Society: An International Journal of Research Policy, 21(2), 150-166.

Prenzler, T., \& Sarre, R. (2008). Protective security in Australia: Scandal, media images and reform. Journal of Policing, Intelligence and Counter Terrorism, 3(2), 23-27.

Quigley, B., Leonard, K., \& Collins, L. (2003). Characteristics of violent bars and bar patrons. Journal of Studies on Alcohol, 64, 765-772.

Reiling, D., \& Nusbaumer, M. (2006). When problem servers pour in problematic places: Alcoholic beverage servers' willingness to serve patrons beyond intoxication. Substance Use and Misuse, 41, 653-668.

Toomey, T. L., Erickson, D. J., Patrek, W., Fletcher, L. A., \& Wagenarr, A. C. (2005). Illegal alcohol sales and use of alcohol control policies at community festivals. Public Health Reports, 120, 165-173.

Toomey, T. L., Fabian, L. A., Erickson, D. J., Wagenaar, A. C., Fletcher, L., \& Lenk, K. M. (2006). Influencing alcohol control policies and practices at community festivals. Journal of Drug Education, 36(1), 15-32.

Victoria Police Licensing Services Division. (2007). Towards "best practice" for effective management of intoxicated young people in entertainment venues. Melbourne: Author. 